\title{
Erratum: Guillermo M., et al. Environmental Impact of Nanoparticles' Application as an Emerging Technology: A Review. Materials 2021, 14, 166
}

\author{
Guillermo Martínez $^{1}$, Manuel Merinero ${ }^{1} \mathbb{D}$, María Pérez-Aranda ${ }^{1}$, Eva María Pérez-Soriano ${ }^{2}$ (D) Tamara Ortiz $^{3} \mathbb{E}$, \\ Eduardo Villamor ${ }^{4}$, Belén Begines ${ }^{1, * \mathbb{D}}$ and Ana Alcudia ${ }^{1, * \mathbb{D}}$
}

1 Department of Organic and Medicinal Chemistry, Faculty of Pharmacy, University of Seville, C/Profesor García González, 2, 41012 Seville, Spain; mtnezmun@gmail.com (G.M.); lolo191995@gmail.com (M.M.); mariapar89@gmail.com (M.P.-A.)

2 Department of Materials Science and Engineering and Transport, Escuela Politécnica Superior, University of Seville, 41011 Seville, Spain; evamps@us.es

3 Department of Normal and Pathological Cytology and Histology, Faculty of Medicine, University of Seville, 41009 Seville, Spain; tortiz@us.es

4 Faculty of Pharmacy, University of Seville, C/Profesor García González, 2, 41012 Seville, Spain; eduardovillamors@gmail.com

* Correspondence: bbegines@us.es (B.B.); aalcudia@us.es (A.A.)

Citation: Martínez, G.; Merinero, M.; Pérez-Aranda, M.; Pérez-Soriano, E.M.; Ortiz, T.; Villamor, E.; Begines, B.; Alcudia, A. Erratum: Guillermo M., et al. Environmental Impact of Nanoparticles' Application as an Emerging Technology: A Review. Materials 2021, 14, 166. Materials 2021, 14, 1710. https://doi.org/10.3390/ ma14071710

Received: 24 February 2021

Accepted: 9 March 2021

Published: 31 March 2021

Publisher's Note: MDPI stays neutral with regard to jurisdictional claims in published maps and institutional affiliations.

Copyright: (C) 2021 by the authors Licensee MDPI, Basel, Switzerland. This article is an open access article distributed under the terms and conditions of the Creative Commons Attribution (CC BY) license (https:// creativecommons.org/licenses/by/ $4.0 /)$.
The authors wish to make the following corrections to this paper [1]:

Change in Author Names (Add a new one)

In the original version of our article [1], the student Eduardo Villamor was not included as an author. To correct this oversight, Eduardo Villamor has now been added to the authorship of the manuscript. The acknowledgements and authors contributions have also been modified.

The corrected author list, affiliation list, authors contribution, and acknowledgements are provided below:

Guillermo Martínez ${ }^{1}$, Manuel Merinero ${ }^{1}$, María Pérez-Aranda ${ }^{1}$, Eva María PérezSoriano $^{2}$, Tamara Ortiz ${ }^{3}$, Eduardo Villamor ${ }^{4}$, Belén Begines ${ }^{1, *}$ and Ana Alcudia ${ }^{1, *}$

${ }^{1}$ Department of Organic and Medicinal Chemistry, Faculty of Pharmacy, University of Seville. C/Profesor García González, 2, 41012 Seville, Spain; mtnezmun@gmail.com (G.M.); lolo191995@gmail.com (M.M.); mariapar89@gmail.com (M.P.-A.)

2 Department of Materials Science and Engineering and Transport, Escuela Politécnica Superior, University of Seville, 41011 Seville, Spain; evamps@us.es

${ }^{3}$ Department of Normal and Pathological Cytology and Histology, Faculty of Medicine, University of Seville, 41009 Seville, Spain; tortiz@us.es

${ }^{4}$ Faculty of Pharmacy, University of Seville. C/Profesor García González, 2, 41012 Seville, Spain; eduardovillamors@gmail.com

*Correspondence: bbegines@us.es (B.B.); aalcudia@us.es (A.A.)

Authors Contributions: Conceptualization and methodology, B.B. and A.A.; investigation, G.M., M.M., M.P.-A., and E.V.; writing-original draft preparation, G.M., M.M., M.P.-A., E.M.P.-S., T.O., and E.V.; writing-review and editing, T.O. and E.M.P.-S.; supervision, B.B., A.A.; funding acquisition, A.A. All authors have read and agreed to the published version of the manuscript.

Acknowledgments: University of Seville Library for providing access to scientific and technical information resources. Some figures have been designed using resources from Freepik.com. 
The authors would like to apologize for any inconvenience caused to the readers by these changes.

\section{Reference}

1. Martínez, G.; Merinero, M.; Pérez-Aranda, M.; Pérez-Soriano, E.M.; Ortiz, T.; Begines, B.; Alcudia, A. Environmental Impact of Nanoparticles' Application as an Emerging Technology: A Review. Materials 2021, 14, 166. [CrossRef] [PubMed] 